\title{
Tracking the role of lightning- produced nitrate for early life with nitrogen isotopes in spark discharge experiments
}

\author{
PATRICK BARTH ${ }^{1}$, EVA E. STÜEKEN ${ }^{1}$, CHRISTIANE \\ HELLING $^{1,2}$ AND MARK CLAIRE $^{1}$ \\ ${ }^{1}$ University of St Andrews \\ ${ }^{2}$ SRON Netherlands Institute for Space Research \\ Presenting Author: pb94@st-andrews.ac.uk
}

In the 1950s, Stanley Miller and Harald Urey proved in their famous experiment that an electric discharge in an abiotic atmosphere of $\mathrm{CH}_{4}, \mathrm{H}_{2}, \mathrm{NH}_{3}$, and $\mathrm{H}_{2} \mathrm{O}$ can lead to the formation of amino acids [1]. Even though the Earth's primordial atmosphere is expected to have been mildly oxidizing rather than reducing [2], this experiment shows the important role of lightning as an energy source in the formation of prebiotic molecules. Subsequent work has shown that in an $\mathrm{N}_{2}$ dominated atmosphere, lightning can initiate abiotic nitrogen fixation through the formation of nitrate $\left(\mathrm{NO}_{3}^{-}\right)$and nitrite $\left(\mathrm{NO}_{2}^{-}\right)$[3] . These forms of nitrogen could not only have facilitated the origin of life but also sustained the early biosphere. So far, however, this hypothesis has been difficult to test with the available rock record, because geochemical fingerprints of this nitrogen source have not been developed. We will present new results from spark discharge experiments in varying atmospheric compositions corresponding to different points in time of Earth's evolution. We show how the production of nitrate and nitrite depends on the $\mathrm{O}_{2} / \mathrm{N}_{2}$ and $\mathrm{CO}_{2} / \mathrm{N}_{2}$-ratio in the gas phase. Furthermore, we investigate the effect of lightning on the isotopic composition of nitrogen in the produced nitrate. We find that the isotopic fractionation between $\mathrm{N}_{2}$ gas and aqueous nitrate depends on atmospheric composition and on other parameters of the experiment such as the electric field strength. By comparison to the sedimentary nitrogen isotope record from the Archean Earth our results allow us to assess for the first time to what degree the origin and early evolution of life may have been influenced by lightning chemistry.

[1] Miller (1953), Science 117, 528

[2] Kasting \& Catling (2003), Annual Review of Astronomy and Astrophysics 41, 429

[3] Cavendish (1788), Philosophical Transactions of the Royal Society of London 78, 261 